\title{
Math Anxiety:
}

\section{Brain Cortical Network Changes in Anticipation of Doing Mathematics.}

Manousos A. Klados ${ }^{1,2,3^{*}}$, Niki Pandria ${ }^{2, *}$, Sifis Micheloyannis ${ }^{4}$, Daniel Margulies ${ }^{1}$ and Panagiotis D. Bamidis ${ }^{2}$

${ }^{1}$ Research Group for Neuroanatomy \& Connectivity, Max Planck Institute for Human Cognitive \& Brain Sciences, Leipzig, Germany

${ }^{2}$ Medical Physics Laboratory, Medical School, Faculty of Health Sciences, Aristotle University of Thessaloniki, Thessaloniki, Greece

${ }^{3}$ School of Life and Health Sciences, Aston University, Birmingham, United Kingdom

${ }^{4}$ Neurophysioloical Research Laboratory (L. Widén), Medical School, University of Crete, Heraklion, Greece

*equal contribution

emails:

Manousos A. Klados: mklados@gmail.com

Niki Pandria: npandria@gmail.com

Sifis Micheloyannis: micheloyannis.sifis@gmail.com

Daniel Margulies: daniel.margulies@gmail.com

Panagiotis Bamidis: bamidis@med.auth.gr

Corresponding Author: Manousos A. Klados, Max Planck Institute for Human

Cognitive \& Brain Sciences, Research Group for Neuroanatomy \& Connectivity, Stephanstraße 1a, 04103 Leipzig, Germany, tel: +49(0)341-9940-2507, fax:+49(0)341-9940-2221, email: klados@cbs.mpg.de

(C) 2017, Elsevier. Licensed under the Creative Commons AttributionNonCommercial-NoDerivatives 4.0 International

http://creativecommons.org/licenses/by-nc-nd/4.0/ 


\begin{abstract}
Following our previous work regarding the involvement of math anxiety (MA) in math-oriented tasks, this study tries to explore the differences in the cerebral networks' topology between self-reported low math-anxious (LMA) and high math-anxious (HMA) individuals, during the anticipation phase prior to a mathematical related experiment. For this reason, multichannel EEG recordings were adopted, while the solution of the inverse problem was applied in a generic head model, in order to obtain the cortical signals. The cortical networks have been computed for each band separately, using the magnitude square coherence metric. The main graph theoretical parameters, showed differences in segregation and integration in almost all EEG bands of the HMAs in comparison to LMAs, indicative of a great influence of the anticipatory anxiety prior to mathematical performance.
\end{abstract}

Keywords: Math anxiety, Functional Connectivity, Graph Theory, Cortical Networks. 


\section{Introduction ${ }^{1}$}

Learning mathematics and arithmetics seems to be challenging for many people (Dowker, 2005). It seems to constitute an important concern for the United States (Martin, Cirino, Sharp, \& Barnes, 2014) as math learning disorder is common (approximately $6 \%$ to $7 \%$ of schoolchildren in USA) among schoolaged children (Barbaresi, Katusic, Colligan, Weaver, \& Jacobsen, 2005; Geary, 1993). There is a broad consensus that poor math performance is slightly or moderately correlated with math anxiety (MA) (Mark H. Ashcraft \& Krause, 2007; Devine, Fawcett, Szücs, \& Dowker, 2012; Jansen et al., 2013; Zakaria, Zain, Ahmad, \& Erlina, 2012). Additionally, children with mathematical learning disabilities are often characterized by disproportionally increased levels of MA (Carey, Hill, Devine, \& Szücs, 2016; Passolunghi, 2011; Rubinsten \& Tannock, 2010).

MA could be characterized as an uneasiness state manifested in mathematical related situations (Cemen, 1987), while its outcome ranges from mild to extreme avoidance (Hembree, 1990) according to the severity of the experienced negative emotions. MA is expressed as a feeling of excessive apprehension, fear or dread over anticipated mathematical events. Although the origins of math anxiety have not been thoroughly investigated (Ashcraft, 2002), many possible risk factors have been considered. The lower-than-

1 Abbreviations: Mathematical Anxiety (MA), Attentional Control Theory (ACT), Low Math-Anxious (LMA), High Math-Anxious (HMA), Abbreviated Math Anxiety Scale (AMAS), Boundary Element Method (BEM), Magnitude Square Coherence (MSC), Density (DEN), Clustering Coefficient (CC), Characteristic Path Length (CPL), Small-World Index (SWN) 
average math abilities, the insufficient working memory, the inadequate motivation, the susceptibility of public embarrassment, a highly demanding, "cold and unsupportive" teacher style might be risk factors for the development of math anxiety (Ashcraft \& Moore, 2009; Ashcraft \& Krause, 2007; Ashcraft, Krause, \& Hopko, 2007; Turner et al., 2002). Moreover, it seems that once the math anxiety is established, it is maintained by a variety of cultural attitudes compromising math performance and leading to avoidance (Ashcraft \& Moore, 2009; Ashcraft \& Krause, 2007). Furthermore, into-class learning might be affected when math anxiety is aroused during a math class. More precisely, whenever the math anxiety is aroused into the classroom the student is distracted from the content of the class focusing on the anxieties and internal worries over math (Ashcraft \& Krause, 2007). In that sense, the mastery of the new information is slowed or degraded (Ashcraft \& Krause, 2007) resulting in math-anxious learn less than non-anxious in the math classroom (Ashcraft \& Moore, 2009).

Even though many correlations between math anxiety and other factors such as gender (Ashcraft \& Faust, 1994), intelligence (Hembree, 1990), motivation and self-confidence (Ashcraft, 2002) have been investigated, the negative correlation between math anxiety and math achievement remains the most troublesome (Ashcraft \& Moore, 2009). Although a negative correlation between math anxiety and math achievement has been revealed (Ashcraft \& Krause, 2007; Hembree, 1990), they can perform comparable to their peers on whole-number arithmetic problems (Faust, 1996; Ashcraft, Kirk, \& Hopko, 1998). However, when percentages, mixed fractions, factoring, equations or even dual tasks appeared, their performance is markedly deteriorated (Ashcraft 
\& Kirk, 2001; Ashcraft, Kirk, \& Hopko, 1998). According to Ashcraft \& Moore (2009), the math anxiety causes an affective drop that underestimates the true math performance regardless of the student's true math mastery. To address the pertinent question regarding the causal linkage between math anxiety and math performance three different theories have been developed (for more information see Carey et al., 2016). The Deficit Theory claims that failure or poor performance in mathematics or test results in increased anxiety about that condition in future (Tobias, 1978). The Debilitating Anxiety Model proposes that anxiety negatively affects performance influencing pre-processing, processing and math knowledge recall (Tobias, 1978; Tobias \& Deutsch, 1980; Wine, 1971). Finally, the Reciprocal Theory supports a bidirectional link between MA and math performance in which math performance and MA affect one another in a vicious cycle (Jansen et al., 2013).

Math anxiety seems to be strongly interrelated with test anxiety whereas the intercorrelations with other anxiety forms range from 0.30 to 0.50 (Ashcraft \& Moore, 2009; Ashcraft, 2002; Hembree, 1990). Although other kinds of anxiety are overlapping, MA should be seen as a separate phenomenon because the coefficient of determination found was 0.37 indicating that only the $37 \%$ of variance could be predicted from the other's variance (Hembree, 1990). To this direction, Faust (1992) found a distinct physiological reactivity (increased heart rate) in demanding mathematical tasks that was not reported in verbal tasks of increasing difficulty (Ashcraft \& Ridley, 2005; Ashcraft, 1995).

The cognitive consequences of MA can be described by Attentional Control Theory (ACT;(Eysenck, Derakshan, Santos, \& Calvo, 2007)). According to $\mathrm{ACT}$, anxiety affects the ability to allocate attentional and cognitive resources 
prior to task performance. Indeed, there are findings supporting that MA affects so the simple quantity and the magnitude manipulations (Maloney, Ansari, \& Fugelsang, 2011; Maloney, Risko, Ansari, \& Fugelsang, 2010), as more complex arithmetic tasks (Ashcraft \& Faust, 1994; Faust, 1996), like the twodigit mental calculations, via the corruption of working memory's performance (Ashcraft \& Ridley, 2005). For more information about the relationship between MA and working memory, there is a comprehensive review by Raghubar and his colleagues (Raghubar, Barnes, \& Hecht, 2010), who reviewed this relationship in the behavioral level, using four different approaches.

Neuroscientific literature concerning MA is very limited, since the underlying neural mechanisms of MA have recently begun to draw the neuroscientists' attention. One of the milestone studies (Lyons \& Beilock, 2012b) in MA research found that math anxious individuals activate more regions related to pain perception during the anticipation of mathematical processing, like the dorsal part of the posterior insula and mid-cingulate cortex. Moreover, Young, Wu, \& Menon (2012) reported that MA activates regions (right amygdala) that regulate negative emotions, while they have also reported that MA inhibits activation in brain regions associated with mathematical reasoning, such as the posterior parietal and dorsolateral prefrontal cortex. Regarding the impact of MA in the brain's electrophysiology, Suárez-Pellicioni, Núñez-Peña, \& Colomé (2013) revealed the relationship between the arithmetic split effect (Ashcraft \& Battaglia, 1978) and the P600/P3b component which was more enhanced and delayed during MA state. In addition, P3 seems also to be affected by MA (Jones, Childers, \& Jiang, 2012) and more specifically by the buying decisions of individuals suffering from MA. One of our recent electroencephalographic 
studies (Klados, Simos, Micheloyannis, Margulies, \& Bamidis, 2015) revealed that MA demonstrated so reduced ERPs at frontocentral and centroparietal locations (between 380-420 ms) during tasks related to working memory and mathematical processing. Our findings were independent of task difficulty/complexity, individual performance, and general state/trait anxiety levels. Following our previous work regarding the involvement of MA in mathoriented tasks, and inspired by the findings of Lyons \& Beilock(2012b), we would like to study how cerebral functional networks are altered by MA, invoked during the anticipation phase prior to a mathematical related experiment. From a phenomenological perspective, it is assumed that during this anticipation phase, the math-anxious individuals will have negative expectations about their ability to cope with the experiment's upcoming mathematical tasks (Barlow, 2004; Barlow, 1991). Anticipatory anxiety is conceptually and biologically distinct from arousal anxiety that is triggered mainly in panic attacks (Heller, Nitschke, Etienne, \& Miller, 1997; Nitschke, Heller, Palmieri, \& Miller, 1999). Although the functional neuroanatomy of anticipatory anxiety is known ( Nitschke et al., 2009; Nitschke, Sarinopoulos, MacKiewicz, Schaefer, \& Davidson, 2006) and it comes in line with the findings of Lyons \& Beilock(2012b), the present study tries to explore the differences in the cerebral networks' topology between self-reported low math-anxious (LMA) and high math-anxious (HMA) individuals. For this reason, multichannel EEG recordings were used in order to compute the cortical networks by employing the methodology proposed by De Vico Fallani et al.(2010). We assume that the aforementioned difference would be apparent in various graph metrics such as clustering coefficient, characteristic path length, small worldness and density, 
while due to the limited neuroscientific literature, and based on similar studies regarding social and general anxiety disorders (Ionescu, Niciu, Mathews, Richards, \& Zarate, 2013; Knyazev, 2011; Liao et al., 2011; Liu et al., 2015; Pannekoek et al., 2013; Roy et al., 2013; Sylvester et al., 2012), we expect to see differences in segregation and integration and increased connectivity in individuals suffering from MA. The novelty of this study lies with the fact that this is the first EEG study that explores the effects of self-reported MA, during a resting state condition anticipating a math-related experiment, in cortical networks' organization.

\section{Materials and Methods}

\subsection{Participants}

One thousand students of the Aristotle University of Thessaloniki were administered the Greek adaptation of the Abbreviated Math Anxiety Scale (AMAS;(Hopko, Mahadevan, Bare, \& Hunt, 2003)). Sixteen students out of sixty three (eight men and eight women) who scored in the upper 15th percentile of the sample distribution ( $\geq 28$ points) and did not meet other exclusionary criteria (non-right handedness, history of neurological or psychiatric disorder) were randomly chosen to form the HMA Group. From the pool of students who scored in the lower 15 th $\%$ tile on AMAS ( $\leq 14$ points) we selected 16 who were individually matched with HMA students on gender and age to form the LMA Group. The two groups did not differ on age (HMA: mean age $=22.21 \pm 2.43$ years, LMA: $22.5 \pm 2.3$ years; $p=0.73$ ) or gender distribution (8 men and 8 women in each), and they were all right handed adults. All participants had normal $(10 / 10)$ or corrected to normal vision. Participants were asked to avoid alcohol intake on the day before and caffeine consumption on the day of the 
experiment; they were also asked to sleep as adequately and comfortably as possible on the night before. All participants were informed about the experiment and signed an informed consent form, while the experimental protocol was approved by the Bioethics Committee of the Medical School of Aristotle University of Thessaloniki (in agreement with the Declaration of Helsinki).

\subsection{Anxiety measures}

AMAS consists of nine items representing common situations faced by students. Participants were asked to rate the level of anxiety associated with each situation on a 5-pint Likert scale (maximum score is 45 points). Despite its brevity, it compares favorably with more extensive self-report measures of math anxiety such as the 98-item Math Anxiety Rating Scale with correlations reaching 0.85 (Ashcraft \& Moore, 2009). The internal consistency of the scale was $\alpha=0.90$.

The Spielberger State-Trait Anxiety Inventory (STAI A-B;(C. Spielberger, Gorsuch, \& Lushene, 1970)) was administered to all participants during electrode preparation to measure situational and trait anxiety levels. The Greek version of this scale has adequate internal consistency $(\alpha=0.92 ;$ (Fountoulakis et al., 2006)).

In addition to AMAS scores on which the two groups differed by design, higher levels of situational anxiety were reported by participants in the HMA as compared to the LMA group, $\mathrm{t}(30)=3.94, \mathrm{p}=0.0001$, yet the two groups showed comparable levels of trait anxiety $(p>0.10$; for more details see (M. A. Klados et al., 2015)). The Pearson correlation between AMAS and state anxiety was moderate $(r=0.575, p=0.001)$ and much lower between AMAS and trait 
anxiety $(r=0.274, p=0.129)$. The second one comes in line in with the original standardization study of AMAS (Hopko, Mahadevan, Bare, \& Hunt, 2003). Although test anxiety invetory (Spielberger, 2010) wasn't administered, at the end of our protocol, the participants were asked to rate the pressure they felt in order to achieve high performance, where there is not any statistically significant difference between our groups $(F(1,30)=3.35, p=0.07)$.

\subsection{Experimental protocol}

Our protocol includes three phases:

a) A resting-state session with eyes opened prior to a mathematical oriented experiment.

b) The experiment, where all participants were administered three working memory tasks (N-back with three levels of load/difficulty) and four arithmetic tasks (addition and multiplication of single or double digit numbers). The order of the tasks was 1-Back, 2-Back, 3- Back, Single Digit Addition, Double-Digit Addition, Single Digit Multiplication, and Double-Digit Multiplication, while each task consisted of 40 trials, except Double-Digit Multiplications involving 20 trials in order to avoid frustration of both groups due to their difficulty, presented in a randomized order across participants (for more information about the tasks please refer to (Klados, Simos, Micheloyannis, Margulies, \& Bamidis, 2015)).

c) c) a resting-state session after the aforementioned experiment.

In order to observe the impact of MA during the anticipation phase of performing mathematical tasks, the resting-state session before the experiment was chosen, since all the participants knew (in accordance with the Declaration of 
Helsinki), prior to the experiment, that they would be asked to solve simple mathematical problems.

\subsection{Electroencephalographic recordings}

Multichannel EEG recordings were recorded in a dark and sound attenuated room, while participants were seated in a comfortable chair and the stimuli were presented on a monitor located about $80 \mathrm{~cm}$ in front of the participant. EEG were recorded from 57 electrode sites according to a modified international 10/10 system using an Electrocap (Fp1, Fp2, F3, F4, C3, C4, P4, O1, O2, F7, F8, T7, T8, P7, P8, Fz, Cz, Pz, TP8, Afz, FCz, CPz, FC1, FC2, CP1, CP2, FC5, FC6, CP5, CP6, Fpz, Oz, F1, POz, F2, C1, C2, P1, P2, AF3, AF4, FC3, FC4, CP3, CP4, PO3, PO4, F5, F6, C5, C6, P5, P6, FT7, FT8, TP7, referred offline to linked mastoids (Klados et al., 2009)). Vertical and horizontal eye movements were recorded through EOG from left/right canthi, supra- and infra-orbital electrodes. All electrode impedances were kept below $2 \mathrm{k} \Omega$. High- and lowpass signals were filtered offline between 0.5 and $45 \mathrm{~Hz}$ (with a notch filter at 47-53Hz) and submitted to an ICA procedure (extended-ICA; (Bell \& Sejnowski, 1995)) in order to identify components reflecting ocular artifacts, which were then filtered using the REGICA methodology (Klados, Papadelis, Braun, \& Bamidis, 2011; Klados, Papadelis, \& Bamidis, 2009) employing the algorithm proposed by Schlolg (Schlögl et al., 2007). Resulting waveforms were visually inspected choosing $20 \mathrm{sec}$ artifact free segments for both sessions. All recordings were performed in mid-morning sessions. 


\subsection{Cortical Activity}

EEG records the activity of the tangential or radial cortical dipoles regarding to the scalp surface. The variation of electrical conductivity among the different head compartments generates the well-known volume conduction problem which seriously affects the functional connectivity analysis (Nolte et al., 2004). To overcome this problem, the cortical activity was obtained from the 57 EEG signals, by employing a realistic head model, a cortical dipole model and the inverse solutions (He, Wang, \& Wu, 1999; M. A. Klados et al., 2013; Mattia et al., 2009). In the current study a generic head model from the reconstruction of 152 normal MRI scans (MNI template http://www.loni.ucla.edu/ICBM/) has been used, while the four different compartments of the head model (scalp, outer and inner skull, cortex) were extracted using the Boundary Element Method (BEM). BEM is implemented in the Brainstorm toolbox (Tadel, Baillet, Mosher, Pantazis, \& Leahy, 2011) which is freely available in http://www.neuroimage.usc.edu/brainstorm. BEM computes the aforementioned compartments by closed triangle meshes with limited number of nodes (in our case we have used 302 nodes). Regarding the regularized solution of the linear inverse problem, we have used the sLORETA algorithm (Pascual-Marqui, 2002), resulting to a transition kernel from our 57 scalp signals to 302 cortical signals.

\subsection{Functional Connectivity and Graph Analysis}

Functional networks were obtained using the magnitude square coherence (MSC; implemented in MATLAB v. 7.10, The MathWorks Inc.). MSC was used because, compared to other metrics, it produces networks closer to the brain's topology (Lithari et al., 2012). In the herein setup we have used 2 sec-long sliding windows with $50 \%$ overlap (for the mathematical formulation of MSC see 
(Klados et al., 2013)). For each participant, MSC produced six weighted and undirected graphs, one for each of six frequency bands: delta $[0.5-4 \mathrm{~Hz}]$, theta [4-8Hz], alpha1 [8-10Hz], alpha2 [10-12Hz], beta [12-30Hz], gamma [30-45Hz]. To investigate the impact of MA into the intrinsic networks' structure the following parameters were employed:

- Density (DEN): graph density indicates how many edges are inside the graph divided by the maximum possible number of edges between the vertices of the graph. This definition is only used for binary graphs, while for weighted graphs we define the density as the sum of all weights divided by the maximum possible number of edges between the vertices multiplied by the maximum value of the current connectivity metric (MSC in this case).

- Clustering Coefficient (CC): CC denotes the fraction of triangles around a node is equivalent to the fraction of node neighbors that are neighbors of each other. For the computation of $\mathrm{CC}$ in weighted networks there are at least four different definitions (Saramäki, Kivelä, Onnela, Kaski, \& Kertész, 2007). However, in the presented work we have used the one proposed by (Onnela, Saramäki, Kertész, \& Kaski, 2005) because it takes into account the weights of all edges in a triangle and it is invariant to the weights permutation in a single triangle.

- Characteristic Path Length (CPL): The characteristic path length is the average shortest path length in the network. It's a measure of the network's integration, meaning that the smaller the CPL gets, the higher the integration of the network is. 
- Small-World Index (SWN): A network small-world topology is a graph in which most nodes are not neighbors, but most of them can be reached from every other in a small number of steps. Humphries and Gurney (Humphries \& Gurney, 2008) have defined the SWN of a network as:

$$
S W N=\frac{C C / C C_{\text {rand }}}{C P L / C P L_{\text {rand }}}
$$

where $C C$ is the cluster coefficient and $C P L$ is the shortest path. Random indices $\left(C C_{\text {rand }}, C P L_{\text {rand }}\right)$ define the mean values of $C C$ and $C P L$ respectively, extracted by fifty surrogate random networks. Each random network was produced by a random rewiring of the observed network (Zalesky, Fornito, \& Bullmore, 2012).

\subsection{Statistical Analysis}

For the graph metrics we followed a multivariate ANOVA design using the values of each graph metric as dependent variables and Anxiety group as a fixed factor. In our analysis, Bonferroni correction has been used to counteract the problem of Type I errors from multiple comparisons. We have also performed a correlational analysis between each one of the graph metrics with the AMAS scores. All the analyses carried out in SPSS v20.

\section{Results}

All the descriptive statistics of the global graph properties, alongside with their corrected p-values are summarized in Table 1. In the results' report below the mean and standard deviation (std) values are excluded since they are summarized in the aforementioned table. 
Table 1 - This table summarizes the descriptive statistics of our five graph properties and for all brainwaves.

\begin{tabular}{|c|c|c|c|c|c|c|}
\hline \multirow{2}{*}{$\begin{array}{c}\text { Graph } \\
\text { Parameters }\end{array}$} & \multirow{2}{*}{$\begin{array}{l}\text { Brain } \\
\text { Wave }\end{array}$} & \multicolumn{2}{|c|}{ Low Math Anxious } & \multicolumn{2}{|c|}{ High Math Anxious } & \multirow{2}{*}{$\begin{array}{c}p- \\
\text { value }\end{array}$} \\
\hline & & mean & std & mean & std & \\
\hline \multirow{6}{*}{$\mathrm{CC}$} & Delta & 0.035577511 & 0.010239979 & 0.053275096 & 0.016125509 & 0.001 \\
\hline & Theta & 0.039259502 & 0.013986454 & 0.054137382 & 0.017015467 & 0.013 \\
\hline & Alpha1 & 0.043096312 & 0.018287829 & 0.055184325 & 0.019009352 & 0.083 \\
\hline & Alpha2 & 0.046183139 & 0.021101631 & 0.057154598 & 0.021297797 & 0.162 \\
\hline & Beta & 0.043497315 & 0.0161073 & 0.05675501 & 0.018778671 & 0.043 \\
\hline & Gamma & 0.036725487 & 0.010403123 & 0.052041466 & 0.016331732 & 0.004 \\
\hline \multirow{6}{*}{$\mathrm{CPL}$} & Delta & 7.12326 & 0.814941 & 5.96913 & 0.752657 & 0.0001 \\
\hline & Theta & 7.03262 & 0.886635 & 6.04078 & 0.756806 & 0.002 \\
\hline & Alpha1 & 6.8608 & 0.958785 & 6.06692 & 0.765101 & 0.025 \\
\hline & Alpha2 & 6.71525 & 1.001151 & 6.04438 & 0.778588 & 0.043 \\
\hline & Beta & 7.06855 & 0.96553 & 6.32053 & 0.715886 & 0.019 \\
\hline & Gamma & 7.43966 & 0.735038 & 6.44811 & 0.86949 & 0.001 \\
\hline \multirow{6}{*}{ DEN } & Delta & 0.067556865 & 0.013509395 & 0.094312916 & 0.022857824 & 0.0001 \\
\hline & Theta & 0.070125316 & 0.017249896 & 0.093281336 & 0.023232371 & 0.004 \\
\hline & Alpha1 & 0.074360791 & 0.021971801 & 0.093503265 & 0.024773482 & 0.031 \\
\hline & Alpha2 & 0.078014225 & 0.025075851 & 0.09506661 & 0.026811623 & 0.08 \\
\hline & Beta & 0.072201808 & 0.019577672 & 0.089980643 & 0.022699289 & 0.027 \\
\hline & Gamma & 0.066495625 & 0.014415445 & 0.086352727 & 0.020491144 & 0.004 \\
\hline \multirow{6}{*}{ SWN } & Delta & 77.96385338 & 28.64833869 & 63.36372088 & 18.01285164 & 0.103 \\
\hline & Theta & 30.36471294 & 11.31799444 & 23.59127425 & 7.981971657 & 0.067 \\
\hline & Alpha1 & 42.22120338 & 20.27508853 & 31.57757706 & 10.97433219 & 0.081 \\
\hline & Alpha2 & 37.65469908 & 17.3927314 & 29.3259635 & 10.82371629 & 0.122 \\
\hline & Beta & 5.933849863 & 1.931405496 & 4.557622781 & 1.408158636 & 0.032 \\
\hline & Gamma & 9.925074738 & 2.279506391 & 7.895594169 & 1.756747333 & 0.009 \\
\hline
\end{tabular}

\subsection{Mean Clustering Coefficient}

Both groups showed significant differences in the mean $\mathrm{CC}$ not only in slow frequency bands such as delta $(F(1 ; 0.731)=13.326 ; p=0.001)$ and theta $(F(1 ; 0.862)=7 ; p=0.013)$ but also in fast frequency bands such as beta $(F(1 ; 0.912)=4.516 ; p=0.043)$ and $\operatorname{gamma}(F(1 ; 0.806)=9.620 ; p=0.004)$. HMA group seems to have greater CC compared to LMA in all frequency bands. The correlational analysis revealed that there is a positive correlation between 
AMAS scores and CC for all frequency bands, while it is significant only for

Delta $(r=0.572 ; p<0.001)$, Theta $(r=0,45 ; p<0,01)$, Beta $(r=0.354 ; p<0.047)$ and

Gamma ( $r=0.518 ; p<0.002)$ bands.

\subsection{Characteristic Path Length}

The main effect of anxiety has found to affect significantly the CPL in all brain band, with delta $(F(1 ; 0.690)=15.457 ; p<0.0001)$, theta $(F(1 ; 0.615)=17.315$; $p=0.02)$, alpha1 $(F(1 ; 0.893)=5.495 ; p=0.025)$, alpha2 $(F(1 ; 0.912)=4.516$; $p=0.043)$, beta $(F(1 ; 0.862)=6.394 ; p=0.019)$ and gamma $(F(1 ; 0.731)=13.326$; $p=0.001)$. HMA's CPL is smaller for each band in contrast to LMA. CPL seems to be also positively correlated with AMAS scores for all brainwaves, while it reaches a significant level for Delta $(r=0.604 ; p<0.0001)$, Theta $(r=0.511 ; p<0.003)$, Alpha1 $(r=0.387 ; p<0.028)$, Beta $(r=0.383 ; p<0.03)$ and Gamma ( $r=0.525 ; p<0.002)$ rhythms.
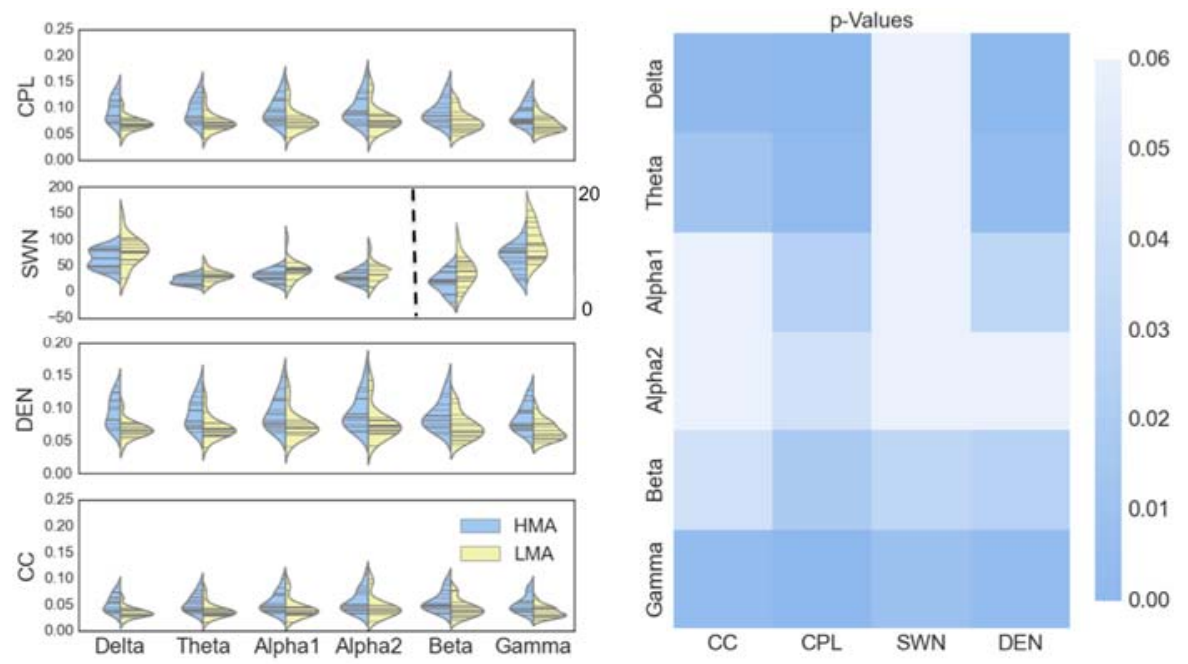

Figure 1 - In this figure we can see the distribution of both group's observations, for each graph parameter used in the current analysis. The grey lines inside the violin plots stand for each observation separately. The p-values' square depicts the significance level of each difference, where darker blue means higher significance level. So our results support that Delta, Theta and Gamma brainwaves' networks seem to be modulated by MA in a greater manner compared to Alpha1 and Beta. The networks formed in higher Alpha band seems to be unaltered by MA, while differences in SWN seem to reach significant level only in the higher frequencies (Beta and Gamma bands), where the violins are zoomed because of their great difference with the rest SWN violins.

\section{Preference for color: only online.}


In the next table (Table 2) we can see the results from the correlational analysis.

Statistical significant correlations are emphasized with bold scripting.

Table 2 - Correlational analysis between the graph properties and the AMAS scores.

\begin{tabular}{|c|c|c|c|}
\hline & & $R$ & $p$-value \\
\hline \multirow{6}{*}{$\mathrm{CC}$} & DELTA & 0.572 & 0.001 \\
\hline & THETA & 0.45 & 0.01 \\
\hline & ALPHA1 & 0.317 & 0.077 \\
\hline & ALPHA2 & 0.251 & 0.165 \\
\hline & BETA & 0.354 & 0.047 \\
\hline & GAMMA & 0.518 & 0.002 \\
\hline \multirow{6}{*}{ CPL } & DELTA & -0.622 & 0.0001 \\
\hline & THETA & -0.543 & 0.001 \\
\hline & ALPHA1 & -0.437 & 0.012 \\
\hline & ALPHA2 & -0.365 & 0.04 \\
\hline & BETA & -0.409 & 0.02 \\
\hline & GAMMA & -0.591 & 0.0001 \\
\hline \multirow{6}{*}{ DEN } & DELTA & 0.604 & 0.0001 \\
\hline & THETA & 0.511 & 0.003 \\
\hline & ALPHA1 & 0.387 & 0.028 \\
\hline & ALPHA2 & 0.313 & 0.082 \\
\hline & BETA & 0.383 & 0.03 \\
\hline & GAMMA & 0.525 & 0.002 \\
\hline \multirow{7}{*}{ SW } & DELTA & -0.32 & 0.074 \\
\hline & THETA & -0.355 & 0.046 \\
\hline & ALPHA1 & -0.335 & 0.061 \\
\hline & ALPHA2 & -0.303 & 0.092 \\
\hline & BETA & -0.411 & 0.02 \\
\hline & GAMMA & -0.458 & 0.008 \\
\hline & GAMMA & 0.544 & 0.001 \\
\hline
\end{tabular}

\subsection{Density}

The density of LMA and HMA groups has found to be significantly altered in delta $(F(1 ; 0.690)=15.782 ; p<0.0001)$, theta $(F(1 ; 0.798)=9.895 ; p=0.004)$, alpha1 $(F(1 ; 0.914)=5.132 ; p=0.031)$, beta $(F(1 ; 0.893)=5.481 ; p=0.027)$ as well as in gamma $(F(1 ; 0.803)=9.687 ; p=0.004)$ band. More precisely, LMA group's 
networks showed lower density than HMA group. DEN is positively correlated with AMAS scores, while these correlations are significant for Delta $(r=0.604 ; p<0.0001)$, Theta $(r=0.511 ; p<0,003)$, Alpha1 $(r=0.387 ; p<0.028)$, Beta $(r=0.383 ; p<0.03)$ and Gamma $(r=0.525 ; p<0.002)$ brainwaves.

\subsection{Small World Metric}

The main effect of anxiety was evident in SWN of the research groups' networks highlighting significant deviation between LMA and HMA in high frequencies, like the beta $(F(1 ; 0.920)=5.064 ; p=0.032)$ and gamma $(F(1 ; 0.817)=7.953$; $p=0.009$ ) bands. The aforementioned results indicate that HMA group showed lower optimal organization compared to LMA group. In contrast to the rest metrics, SWN is negatively correlated with AMAS scores, while these negative correlations are significant only for Theta $(r=-0.335 ; p<0.046)$, Beta ( $r=-$ $0.411 ; p<0.02)$ and Gamma $(r=-0.458 ; p<0.001)$ brainwaves.

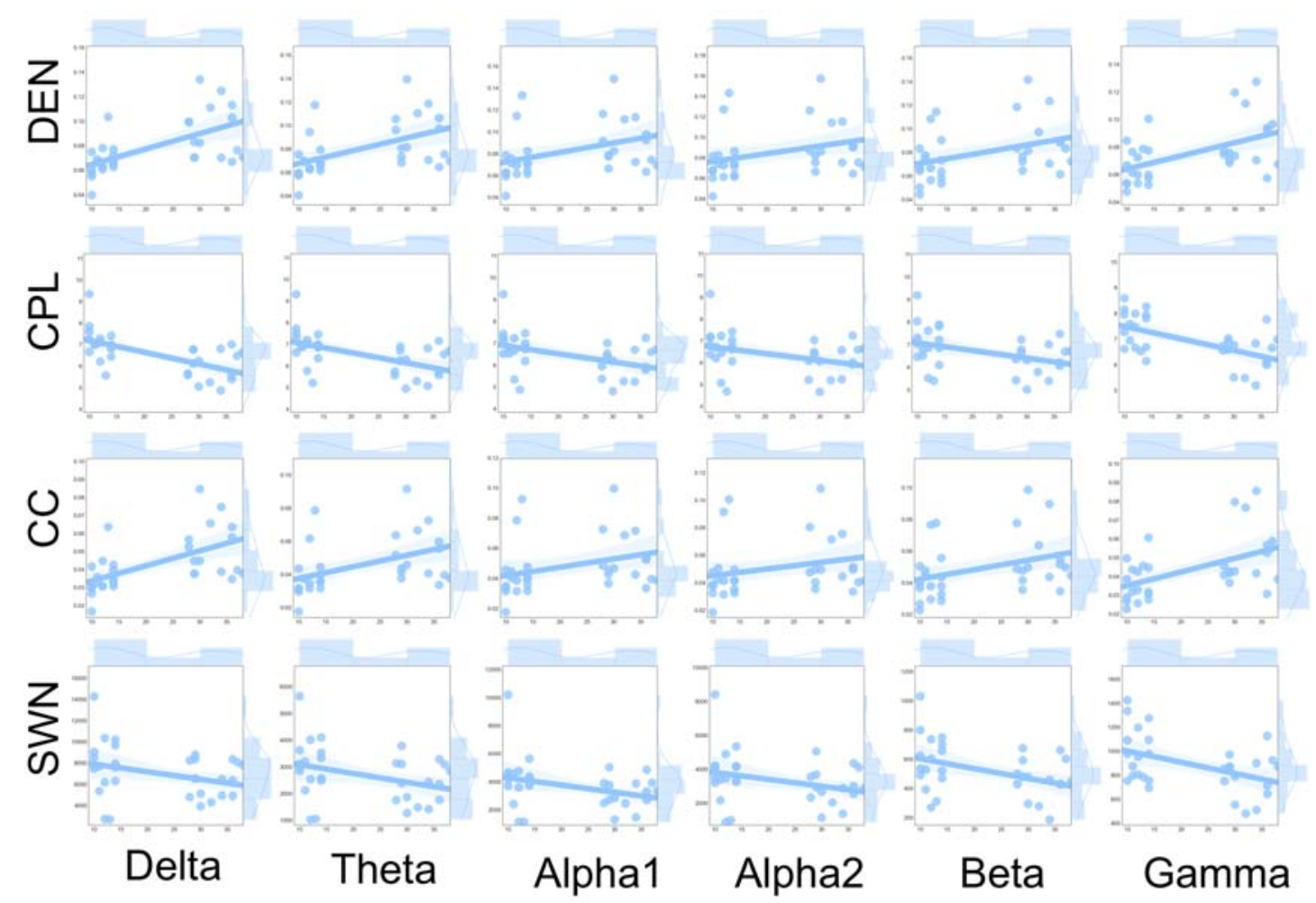

Figure 2 - This grid contains the scatter plots, with the linear regression line, for each graph parameter and each brainwave. The $\mathrm{x}$-axis represents the AMAS scores, while the $y$-axis stands for each metric separately. Outside of each scatter plot we can see the distributions of AMAS scores (up) 
and each metric's values (right). The distributions of AMAS scores are constant while the distributions right from the scatter plots change according to each metric. For the correlation values alongside with the significant level you can refer to Table 2 .

Preference for color: only online.

\section{Discussion}

We analyzed the brain networks in healthy individuals with MA in the anticipation of an upcoming mathematical task. For network analyses we used tools from modern network theory i.e. graph theory. Individuals with HMA, showed more effective functional organization, in contrast to their LMA peers, because their networks showed more reactivity since the upcoming math task was accompanied with the feeling of anxiety, influencing the brain networks in their try to regulate negative emotions. The major difference between this study and our previous one (Klados, Simos, Micheloyannis, Margulies, \& Bamidis, 2015 ) is that this study investigates the impact of MA in resting-state cortical networks obtained before the whole experiment, where the participants knew that they are going to participate in a mathematical related experiment, while the previous one examined the impact of MA in the sensor level evoked potentials during mathematical and working memory tasks. The innovation of this study lies with the fact that this is the first EEG study that explores the effects of self-reported MA, during a resting state condition anticipating a mathrelated experiment, in cortical networks' organization.

Small-world network organization is the optimum network organization balancing between local activation and widespread effective information transfer. In our study, networks of both groups showed small world network properties with significant differences in high frequencies (beta and gamma 
bands) with lower values for the HMA group. Beta and gamma bands express mainly local activations (Bidelman, 2015; Herrmann, Strüber, Helfrich, \& Engel, 2015; Lewis, Wang, \& Bastiaansen, 2015), while the lower SWN index is explained as the result of local activation and expression of the local desynchronization during the anxiety reactivity. Moreover, the CC shows higher values in HMA in the same bands as a sign of higher local segregation. Simultaneously, for these bands, CPL is lower as an expression of more efficient organization of the segregated region.

Although indicative findings of local activations exist in other fMRI studies, there are only a few fMRI related to math anxiety. Two of them (Lyons \& Beilock, 2012a, 2012b) examined the brain reactivity during the anticipation phase of doing math and showed local activations in math anxious individuals. It was found that while anticipating an upcoming math task, regions associated with pain were activated in bilateral dorso-posterior insula. This local activation explains our findings related to beta and gamma bands i.e. lower Small World Index (more desynchronization), the higher CC (increased nodal activity, higher segregation), and the shorter CPL (shorter path length as a result of more efficient remote connections).

Delta as well as theta band shows higher CC and shorter CPL in HMA group i.e. increased nodal activity and more efficient remote connections. Both show SWN properties without any significant differences between LMA and HMA groups. HMA individuals need more effort in order to regulate their negative emotional response and reach comparable performance to LMA individuals (Pletzer, Kronbichler, Nuerk, \& Kerschbaum, 2015). The higher delta band efficiency could be the result of the inhibition of other processes that 
interfere with the resolution of the anticipating reactivity to math tasks (Harmony, 2013). Additionally, the cognitive processes, such as those during the math anxiety in HMAs, are assumed to be related to some suppression of the default mode network and this is accompanied with increased delta band activation (Chen, Feng, Zhao, Yin, \& Wang, 2008; Greicius, Krasnow, Reiss, \& Menon, 2003).

Theta band, which seems more effective in HMAs, can be explained as a strong emotional expression in the anticipation of taking part in a math-related experiment. Theta band activity has been found to be enhanced as response to emotional expressions (Luo et al., 2013). An additional reason for higher theta band activation may be the a high proportion of working memory resources needed to control negative emotions in contrast to LMAs where the working memory is more efficient (Derakshan \& Eysenck, 2009; Klimesch, 1999; Pletzer et al., 2015).

Alpha1 and Alpha2 bands have different functional roles, and they correspond to different cognitive sub-domains related to local activities, information transfer or working memory (Dunst et al., 2014; Klimesch, 1999). Although our findings show both alphas have more efficient remote connections in HMAs, we haven't found any differences in segregation. Moreover, our two groups also differ in their networks' density, while HMA group seems to have more dense networks for all frequency bands, which is assumed as a sign of more intense brain network organization in HMAs.

In our last analysis, the self-reported scores of math anxiety were correlated with the graph properties. There was a positive correlation between 
CC (segregation) and density and a negative correlation between CPL (integration) and SWN indexes, while the correlation trend was constant across frequency bands for each parameter separately. These findings intonate the differences of the graph parameters of the different bands between HMAs and LMAs. It shows that the graph parameters values i.e. the network reactivities are analog to the (anticipating) cognitive math brain functions.

The aforementioned findings should be considered in the light of some limitations. The first limitation considers the sample size, where our sample size of 16 participants per group is supposed to be the minimum sample size for a 2-sided test (Allen, 2011) (parameters:, effect size $=1, \alpha=0.05$ and the $\beta=0.2$ ), according to the statistical rule of thumb (Van Belle, 2008). However, an increased sample size could provide us with more confidence about the generalization of the presented conclusions. Although our groups didn't have a statistically significant difference regarding the pressure felt in order to have high performance, the lack of a test anxiety assessment, which may interfere with the observed differences is another one limitation of the current study. This probably could be solved if the anticipation phase prior to a mathematical task could be compared with the anticipation phase before a verbal task. Although this is not feasible with the current design, the interference of test anxiety in the neural basis of MA should be addressed in a future study.

\section{Conclusions}

In summary, brain network changes in HMA individuals during the anticipation phase of participating in a math related experiment, were studied using EEG signals. The main network parameters, using graph analysis, 
showed differences in segregation and integration in almost all EEG bands of

the HMAs in comparison to LMAs, indicative of a great influence of the anticipatory anxiety prior to mathematical performance.

\section{References}

Allen, J. C. (2011). Sample Size Calculation for Two Independent Groups: A Useful Rule of Thumb. Proceedings of Singapore Healthcare, 20(2), 138-140. http://doi.org/10.1177/201010581102000213

Ashcraft, M. H. (1995). Cognitive Psychology and Simple Arithmetic: A Review and Summary of New Directions. Mathematical Cognition.

Ashcraft, M. H. (2002). Math Anxiety: Personal, Educational, and Cognitive Consequences. Current Directions in Psychological Science, 11(5), 181-185. http://doi.org/10.1111/1467-8721.00196

Ashcraft, M. H., \& Battaglia, J. (1978). Cognitive arithmetic: Evidence for retrieval and decision processes in mental addition. Journal of Experimental Psychology: Human Learning \& Memory, 4(5), 527-538. http://doi.org/10.1037/0278-7393.4.5.527

Ashcraft, M. H., \& Faust, M. W. (1994). Mathematics anxiety and mental arithmetic performance: An exploratory investigation. Cognition \& Emotion, 8(2), 97-125. http://doi.org/10.1080/02699939408408931

Ashcraft, M. H., \& Kirk, E. P. (2001). The relationships among working memory, math anxiety, and performance. Journal of Experimental Psychology: General, 130(2), 224-237. http://doi.org/10.1037/0096-3445.130.2.224

Ashcraft, M. H., \& Krause, J. A. (2007). Working memory, math performance, and math anxiety. Psychonomic Bulletin \& Review, 14(2), 243-248. http://doi.org/10.3758/BF03194059

Ashcraft, M. H., Krause, J. A., \& Hopko, D. R. (2007). Is math anxiety a mathematical learning disability. Why Is Math so Hard for Some Children, (January 2007), 329348.

Ashcraft, M. H., \& Moore, A. M. (2009). Mathematics Anxiety and the Affective Drop in Performance. Journal of Psychoeducational Assessment, 27(3), 197-205. http://doi.org/10.1177/0734282908330580

Ashcraft, M. H., \& Ridley, K. S. (2005). Math Anxiety and Its Cognitive Consequences. In Jamie I. D. Campbell (Ed.), Handbook of mathematical cognition (pp. 315-327). New York, NY: Psychology Press Ltd.

Barbaresi, W. J., Katusic, S. K., Colligan, R. C., Weaver, A. L., \& Jacobsen, S. J. (2005). Math Learning Disorder: Incidence in a Population-Based Birth Cohort, 1976-82, Rochester, Minn. Ambulatory Pediatrics, 5(5), 281. http://doi.org/10.1367/A04209R.1

Barlow, D. H. (1991). Disorders of Emotion. Psychological Inquiry, 2(1), 58-71. http://doi.org/10.1207/s15327965pli0201_15

Barlow, D. H. (2004). Anxiety and its disorders: The nature and treatment of anxiety and panic. Guilford press. 
Bell, A. J., \& Sejnowski, T. J. (1995). An Information-Maximization Approach to Blind Separation and Blind Deconvolution. Neural Computation, 7(6), 1129-1159. http://doi.org/10.1162/neco.1995.7.6.1129

Bidelman, G. M. (2015). Induced neural beta oscillations predict categorical speech perception abilities. Brain and Language, 141, 62-9. http://doi.org/10.1016/j.bandl.2014.11.003

Carey, E., Hill, F., Devine, A., \& Szücs, D. (2016). The chicken or the egg? The direction of the relationship between mathematics anxiety and mathematics performance. Frontiers in Psychology, 6(JAN), 1-6. http://doi.org/10.3389/fpsyg.2015.01987

Cemen, P. B. (1987). The Nature of Mathematics Anxiety. ERIC.

Chen, A. C. N., Feng, W., Zhao, H., Yin, Y., \& Wang, P. (2008). EEG default mode network in the human brain: Spectral regional field powers. NeuroImage, 41(2), 561-574. http://doi.org/10.1016/j.neuroimage.2007.12.064

De Vico Fallani, F., Maglione, A., Babiloni, F., Mattia, D., Astolfi, L., Vecchiato, G., ... Micheloyannis, S. (2010). Cortical network analysis in patients affected by schizophrenia. Brain Topography, 23(2), 214-20. http://doi.org/10.1007/s10548010-0133-2

Derakshan, N., \& Eysenck, M. W. (2009). Anxiety, processing efficiency, and cognitive performance: New developments from attentional control theory. European Psychologist, 14(2), 168-176. http://doi.org/10.1027/1016-9040.14.2.168

Devine, A., Fawcett, K., Szűcs, D., \& Dowker, A. (2012). Gender differences in mathematics anxiety and the relation to mathematics performance while controlling for test anxiety. Behavioral and Brain Functions, 8(1), 33. http://doi.org/10.1186/1744-9081-8-33

Dowker, A. (2005). Individual Differences in Arithmetic. Individual differences in arithmetic: Implications for psychology, neuroscience and education. http://doi.org/10.4324/9780203324899

Dunst, B., Benedek, M., Jauk, E., Bergner, S., Koschutnig, K., Sommer, M., ... Neubauer, A. C. (2014). Neural efficiency as a function of task demands. Intelligence, 42, 22-30. http://doi.org/10.1016/j.intell.2013.09.005

Eysenck, M. W., Derakshan, N., Santos, R., \& Calvo, M. G. (2007). Anxiety and cognitive performance: attentional control theory. Emotion (Washington, D.C.), 7(2), 336-53. http://doi.org/10.1037/1528-3542.7.2.336

Faust, M. W. (1992). Analysis of physiological reactivity in mathematics anxiety. Bowling Green University.

Faust, M. W. (1996). Mathematics Anxiety Effects in Simple and Complex Addition. Mathematical Cognition, 2(1), 25-62. http://doi.org/10.1080/135467996387534

Fountoulakis, K. N., Papadopoulou, M., Kleanthous, S., Papadopoulou, A., Bizeli, V., Nimatoudis, I., ... Kaprinis, G. S. (2006). Reliability and psychometric properties of the Greek translation of the State-Trait Anxiety Inventory form Y: preliminary data. Annals of General Psychiatry, 5, 2. http://doi.org/10.1186/1744-859X-5-2

Geary, D. C. (1993). Mathematical Disabilities. Children's Mathematical Development: Research and Practical Applications, (September), 155-187. http://doi.org/10.1037/10163-001

Greicius, M. D., Krasnow, B., Reiss, A. L., \& Menon, V. (2003). Functional connectivity in the resting brain: a network analysis of the default mode hypothesis. Proceedings of the National Academy of Sciences of the United States of America, 100(1), 253-258. http://doi.org/10.1073/pnas.0135058100 
H., M., Ashcraft, P., E., Kirk, \& Hopko, D. (1998). On the cognitive consequences of mathematics anxiety. In C. Donlan (Ed.), The development of mathematical skills. Studies in developmental psychology. (pp. 175-196). Hove, England: Psychology Press/Taylor \& Francis (UK).

Harmony, T. (2013). The functional significance of delta oscillations in cognitive processing. Frontiers in Integrative Neuroscience, 7, 83. http://doi.org/10.3389/fnint.2013.00083

He, B., Wang, Y., \& Wu, D. (1999). Estimating cortical potentials from scalp EEG's in a realistically shaped inhomogeneous head model by means of the boundary element method. IEEE Transactions on Bio-Medical Engineering, 46(10), 1264-8. Retrieved from http://www.ncbi.nlm.nih.gov/pubmed/10513133

Heller, W., Nitschke, J. B., Etienne, M. A., \& Miller, G. A. (1997). Patterns of regional brain activity differentiate types of anxiety. Journal of Abnormal Psychology, 106(3), 376385. http://doi.org/10.1037/0021-843X.106.3.376

Hembree, R. (1990). The Nature, Effects, and Relief of Mathematics Anxiety. Journal for Research in Mathematics Education, 21(1), 33. http://doi.org/10.2307/749455

Herrmann, C. S., Strüber, D., Helfrich, R. F., \& Engel, A. K. (2015). EEG oscillations: From correlation to causality. International Journal of Psychophysiology: Official Journal of the International Organization of Psychophysiology. http://doi.org/10.1016/j.ijpsycho.2015.02.003

Hopko, D. R., Mahadevan, R., Bare, R. L., \& Hunt, M. K. (2003). The Abbreviated Math Anxiety Scale (AMAS): construction, validity, and reliability. Assessment, 10(2), 178-82. Retrieved from http://www.ncbi.nlm.nih.gov/pubmed/12801189

Humphries, M. D., \& Gurney, K. (2008). Network "small-world-ness": a quantitative method for determining canonical network equivalence. PloS One, 3(4), e0002051. http://doi.org/10.1371/journal.pone.0002051

Ionescu, D. F., Niciu, M. J., Mathews, D. C., Richards, E. M., \& Zarate, C. A. (2013). NEUROBIOLOGY OF ANXIOUS DEPRESSION: A REVIEW. Depression and Anxiety, 30(4), 374-385. http://doi.org/10.1002/da.22095

Jansen, B. R. J., Louwerse, J., Straatemeier, M., Van der Ven, S. H. G., Klinkenberg, S., \& Van der Maas, H. L. J. (2013). The influence of experiencing success in math on math anxiety, perceived math competence, and math performance. Learning and Individual Differences, 24, 190-197. http://doi.org/10.1016/j.lindif.2012.12.014

Jones, W. J., Childers, T. L., \& Jiang, Y. (2012). The shopping brain: Math anxiety modulates brain responses to buying decisions. Biological Psychology, 89(1), 201213. http://doi.org/10.1016/j.biopsycho.2011.10.011

Klados, M. A., Frantzidis, C., Vivas, A. B., Papadelis, C., Lithari, C., Pappas, C., \& Bamidis, P. D. (2009). A Framework Combining Delta Event-Related Oscillations (EROs) and Synchronisation Effects (ERD/ERS) to Study Emotional Processing. Computational Intelligence and Neuroscience, 2009, 1-16. http://doi.org/10.1155/2009/549419

Klados, M. A., Kanatsouli, K., Antoniou, I., Babiloni, F., Tsirka, V., Bamidis, P. D., \& Micheloyannis, S. (2013). A Graph theoretical approach to study the organization of the cortical networks during different mathematical tasks. PloS One, 8(8), e71800. http://doi.org/10.1371/journal.pone.0071800

Klados, M. A., Papadelis, C., Braun, C., \& Bamidis, P. D. (2011). REG-ICA: A hybrid methodology combining Blind Source Separation and regression techniques for the rejection of ocular artifacts. Biomedical Signal Processing and Control, 6(3), 291300. http://doi.org/10.1016/j.bspc.2011.02.001 
Klados, M. a., Papadelis, C. L., \& Bamidis, P. D. (2009). REG-ICA: A new hybrid method for EOG Artifact Rejection. 2009 9th International Conference on Information Technology and Applications in Biomedicine, 1-4. http://doi.org/10.1109/ITAB.2009.5394295

Klados, M. A., Simos, P., Micheloyannis, S., Margulies, D., \& Bamidis, P. D. (2015). ERP measures of math anxiety: how math anxiety affects working memory and mental calculation tasks? Frontiers in Behavioral Neuroscience, 9. http://doi.org/10.3389/fnbeh.2015.00282

Klimesch, W. (1999). EEG alpha and theta oscillations reflect cognitive and memory performance: A review and analysis. Brain Research Reviews. http://doi.org/10.1016/S0165-0173(98)00056-3

Knyazev, G. G. (2011). Cross-frequency coupling of brain oscillations: An impact of state anxiety. International Journal of Psychophysiology, 80(3), 236-245. http://doi.org/10.1016/j.ijpsycho.2011.03.013

Lewis, A. G., Wang, L., \& Bastiaansen, M. (n.d.). Fast oscillatory dynamics during language comprehension: Unification versus maintenance and prediction? http://doi.org/10.1016/j.bandl.2015.01.003

Liao, W., Xu, Q., Mantini, D., Ding, J., Machado-de-Sousa, J. P., Hallak, J. E. C., ... Chen, H. (2011). Altered gray matter morphometry and resting-state functional and structural connectivity in social anxiety disorder. Brain Research, 1388, 167-177. http://doi.org/10.1016/j.brainres.2011.03.018

Lithari, C., Klados, M. A., Papadelis, C., Pappas, C., Albani, M., \& Bamidis, P. D. (2012). How does the metric choice affect brain functional connectivity networks? Biomedical Signal Processing and Control, 7(3), 228-236. http://doi.org/10.1016/j.bspc.2011.05.004

Liu, F., Zhu, C., Wang, Y., Guo, W., Li, M., Wang, W., ... Chen, H. (2015). Disrupted cortical hubs in functional brain networks in social anxiety disorder. Clinical Neurophysiology, 126(9), 1711-1716. http://doi.org/10.1016/j.clinph.2014.11.014

Luo, Q., Cheng, X., Holroyd, T., Xu, D., Carver, F., \& Blair, R. J. (2013). Theta band activity in response to emotional expressions and its relationship with gamma band activity as revealed by MEG and advanced beamformer source imaging. Frontiers in Human Neuroscience, 7, 940. http://doi.org/10.3389/fnhum.2013.00940

Lyons, I. M., \& Beilock, S. L. (2012a). Mathematics Anxiety: Separating the Math from the Anxiety. Cerebral Cortex, 22(9), 2102-2110. http://doi.org/10.1093/cercor/bhr289

Lyons, I. M., \& Beilock, S. L. (2012b). When math hurts: math anxiety predicts pain network activation in anticipation of doing math. PloS One, 7(10), e48076. http://doi.org/10.1371/journal.pone.0048076

Maloney, E. A., Ansari, D., \& Fugelsang, J. A. (2011). The effect of mathematics anxiety on the processing of numerical magnitude. Quarterly Journal of Experimental Psychology (2006), 64(1), 10-16. http://doi.org/10.1080/17470218.2010.533278

Maloney, E. A., Risko, E. F., Ansari, D., \& Fugelsang, J. (2010). Mathematics anxiety affects counting but not subitizing during visual enumeration. Cognition, 114(2), 293-7. http://doi.org/10.1016/j.cognition.2009.09.013

Martin, R. B., Cirino, P. T., Sharp, C., \& Barnes, M. (2014). Number and counting skills in kindergarten as predictors of grade 1 mathematical skills. Learning and Individual Differences, 34, 12-23. http://doi.org/10.1016/j.lindif.2014.05.006

Mattia, D., Cincotti, F., Astolfi, L., de Vico Fallani, F., Scivoletto, G., Marciani, M. G., \& 
Babiloni, F. (2009). Motor cortical responsiveness to attempted movements in tetraplegia: evidence from neuroelectrical imaging. Clinical Neurophysiology: Official Journal of the International Federation of Clinical Neurophysiology, 120(1), 181-9. http://doi.org/10.1016/j.clinph.2008.09.023

Nitschke, J. B., Heller, W., Palmieri, P. A., \& Miller, G. A. (1999). Contrasting patterns of brain activity in anxious apprehension and anxious arousal. Psychophysiology, 36(5), 628-637. http://doi.org/10.1017/S0048577299972013

Nitschke, J. B., Sarinopoulos, I., MacKiewicz, K. L., Schaefer, H. S., \& Davidson, R. J. (2006). Functional neuroanatomy of aversion and its anticipation. NeuroImage, 29(1), 106116. http://doi.org/10.1016/j.neuroimage.2005.06.068

Nitschke, J. B., Sarinopoulos, I., Oathes, D. J., Johnstone, T., Whalen, P. J., Davidson, R. J., \& Kalin, N. H. (2009). Anticipatory activation in the Amygdala and Anterior Cingulate in generalized anxiety disorder and prediction of reatment response. American Journal of Psychiatry, 166(3), 302-310. http://doi.org/10.1176/appi.ajp.2008.07101682

Nolte, G., Bai, O., Wheaton, L., Mari, Z., Vorbach, S., \& Hallett, M. (2004). Identifying true brain interaction from EEG data using the imaginary part of coherency. Clinical Neurophysiology: Official Journal of the International Federation of Clinical Neurophysiology, 115(10), 2292-307. http://doi.org/10.1016/j.clinph.2004.04.029

Onnela, J.-P., Saramäki, J., Kertész, J., \& Kaski, K. (2005). Intensity and coherence of motifs in weighted complex networks. Physical Review E, 71(6), 65103. http://doi.org/10.1103/PhysRevE.71.065103

Pannekoek, J. N., Veer, I. M., van Tol, M.-J., van der Werff, S. J. A., Demenescu, L. R., Aleman, A., ... van der Wee, N. J. A. (2013). Resting-state functional connectivity abnormalities in limbic and salience networks in social anxiety disorder without comorbidity. European Neuropsychopharmacology, 23(3), 186-195. http://doi.org/10.1016/j.euroneuro.2012.04.018

Pascual-Marqui, R. D. (2002). Standardized low-resolution brain electromagnetic tomography (sLORETA): technical details. Methods and Findings in Experimental and Clinical Pharmacology, 24 Suppl D, 5-12. Retrieved from http://www.ncbi.nlm.nih.gov/pubmed/12575463

Passolunghi, M. C. (2011). Cognitive and Emotional Factors in Children with Mathematical Learning Disabilities. International Journal of Disability, Development and Education, 58(1), 61-73. http://doi.org/10.1080/1034912X.2011.547351

Pletzer, B., Kronbichler, M., Nuerk, H.-C., \& Kerschbaum, H. H. (2015). Mathematics anxiety reduces default mode network deactivation in response to numerical tasks. Frontiers in Human Neuroscience, 9, 202. http://doi.org/10.3389/fnhum.2015.00202

Raghubar, K. P., Barnes, M. A., \& Hecht, S. A. (2010). Working memory and mathematics: A review of developmental, individual difference, and cognitive approaches. Learning and Individual Differences, 20(2), 110-122. http://doi.org/10.1016/j.lindif.2009.10.005

Roy, A. K., Fudge, J. L., Kelly, C., Perry, J. S. A., Daniele, T., Carlisi, C., ... Ernst, M. (2013). Intrinsic Functional Connectivity of Amygdala-Based Networks in Adolescent Generalized Anxiety Disorder. Journal of the American Academy of Child \& Adolescent Psychiatry, 52(3), 290-299.e2. http://doi.org/10.1016/j.jaac.2012.12.010

Rubinsten, O., \& Tannock, R. (2010). Mathematics anxiety in children with developmental dyscalculia. Behavioral and Brain Functions, 6(1), 46. 
http://doi.org/10.1186/1744-9081-6-46

Saramäki, J., Kivelä, M., Onnela, J.-P., Kaski, K., \& Kertész, J. (2007). Generalizations of the clustering coefficient to weighted complex networks. Physical Review E, 75(2), 27105. http://doi.org/10.1103/PhysRevE.75.027105

Schlögl, A., Keinrath, C., Zimmermann, D., Scherer, R., Leeb, R., \& Pfurtscheller, G. (2007). A fully automated correction method of EOG artifacts in EEG recordings. Clinical Neurophysiology: Official Journal of the International Federation of Clinical Neurophysiology, 118(1), 98-104. http://doi.org/10.1016/j.clinph.2006.09.003

Spielberger, C. D. (2010). Test Anxiety Inventory. In The Corsini Encyclopedia of Psychology. Hoboken, NJ, USA: John Wiley \& Sons, Inc. http://doi.org/10.1002/9780470479216.corpsy0985

Spielberger, C., Gorsuch, R., \& Lushene, R. (1970). Manual for the state-trait anxiety inventory.

Suárez-Pellicioni, M., Núñez-Peña, M. I., \& Colomé, À. (2013). Abnormal Error Monitoring in Math-Anxious Individuals: Evidence from Error-Related Brain Potentials. PLoS ONE, 8(11), e81143. http://doi.org/10.1371/journal.pone.0081143

Sylvester, C. M., Corbetta, M., Raichle, M. E., Rodebaugh, T. L., Schlaggar, B. L., Sheline, Y. I., ... Lenze, E. J. (2012). Functional network dysfunction in anxiety and anxiety disorders. Trends in Neurosciences, 35(9), 527-535. http://doi.org/10.1016/j.tins.2012.04.012

Tadel, F., Baillet, S., Mosher, J. C., Pantazis, D., \& Leahy, R. M. (2011). Brainstorm: a userfriendly application for MEG/EEG analysis. Computational Intelligence and Neuroscience, 2011, 879716. http://doi.org/10.1155/2011/879716

Tobias, S. (1978). Anxiety and cognitive processing of instruction. In R.Schwarzer (Ed.), Self-Related Cognitions in Anxiety and Motivation (pp. 35-54). (Hillsdale, NJ:Lawrence ErlbaumAssociates.

Tobias, S., \& Deutsch, T. (1980). Prior achievement, anxiety and instructional method. Paper Presented at the Annual Meeting of the Americal Psychological Association (88th, Montreal, Quebec, Canada, September 1-5, 1980).

Turner, J. C., Midgley, C., Meyer, D. K., Gheen, M., Anderman, E. M., Kang, Y., \& Patrick, H. (2002). The classroom environment and students' reports of avoidance strategies in mathematics: A multimethod study. Journal of Educational Psychology, 94(1), 88106. http://doi.org/10.1037/0022-0663.94.1.88

Van Belle, G. (2008). Statistical rules of thumb. Wiley.

Wine, J. (1971). Test anxiety and direction of attention. Psychological Bulletin, 76(2), 92104. http://doi.org/10.1037/h0031332

Young, C. B., Wu, S. S., \& Menon, V. (2012). The neurodevelopmental basis of math anxiety. Psychological Science, 23(5), 492-501. http://doi.org/10.1177/0956797611429134

Zakaria, E., Zain, N. M., Ahmad, N. A., \& Erlina, A. (2012). Mathematics anxiety and achievement among secondary school students. American Journal of Applied Sciences, 9(11), 1828-1832. http://doi.org/10.3844/ajassp.2012.1828.1832

Zalesky, A., Fornito, A., \& Bullmore, E. (2012). On the use of correlation as a measure of network connectivity. NeuroImage, 60(4), 2096-106. http://doi.org/10.1016/j.neuroimage.2012.02.001 